\title{
Assessing high compositional differences of beetle assemblages across vertical woodland strata in the New Forest, Hampshire, England
}

\author{
Sholto Holdsworth, Peter M. Hammond and Paul Eggleton \\ Soil Biodiversity Group, Life Sciences Department, Natural History Museum, London, UK
}

\begin{abstract}
Closed-canopy woodlands are complex ecosystems with strong vertical environmental stratification. The degree to which this vertical stratification has led to compartmentalisation in invertebrate assemblages in temperate woodlands has been researched to a limited extent, yet there are still gaps in our understanding. Here, we used five different sampling methods to sample beetles across vertical strata of nine woodland sites in the New Forest National Park, Hampshire, England. The sampling methods yielded 2412 individuals across 157 species, of which 46 were significant indicator species for one stratum or a combination of strata. Multivariate analysis of composition showed a strong separation at a subfamily level between strata, with many only found in a single stratum. This suggests a strongly compartmentalised vertical stratification of the beetle assemblages at both species and higher taxonomic levels. Our results display that multiple strata need to be sampled to obtain true estimates of overall beetle species richness in woodlands and forests. Limitations in using a single sampling method and biases using mixed sampling method protocols across a vertical transect are also discussed.
\end{abstract}

\section{ARTICLE HISTORY}

Received 2 December 2015

Accepted 20 May 2016

\section{KEYWORDS}

Beetles; strata; woodland sampling methods; indicator species

\section{Introduction}

Beetles (Coleoptera) are one of the most diverse major groups of animals on the planet, inhabiting almost all terrestrial ecosystems (New 2010). Beetles have radiated to inhabit a wide range of different niches, with many species inhabiting specific microhabitats (Barton et al. 2009). As well as being hyper diverse, beetles contribute importantly to ecological processes within woodlands, from food webs and nutrient flow to litter decomposition (Lassua et al. 2005).

The contribution beetle assemblages make to ecological processes is thought to be particularly important in forest environments, where vertical stratification may generate many different niches (Thomas and Packham 2007). It is unclear, however, whether there is a strong separation of vertical strata in temperate woodlands or if it is one gradually

CONTACT Sholto Holdsworth s.holdsworth@nhm.ac.uk B Soil Biodiversity Group, Life Sciences Department, Natural History Museum, Cromwell Road, London SW7 5BD, UK

(4) Supplemental data for this article can be accessed here.

๑) 2016 Informa UK Limited, trading as Taylor \& Francis Group 
changing environment (Baker and Wilson 2000). This uncertainty regarding the degree of compartmentalisation is perhaps a result of the strata in temperate woodlands being less marked when compared with observations in tropical forests, possibly because of a lack of distinct vertical gradients of microclimatic and biotic factors in temperate woodlands (Basset et al. 2003).

It is important to gain an understanding of the specific behaviours of invertebrates within and between the vertical strata. One reason being $40 \%$ of the 492 beetle species which are endangered, vulnerable or rare according to Britain's Red Data Book (Shirt 1987) are associated with woodlands. This is particularly the case in ancient woodlands which harbour around 90 species that are either endangered or vulnerable (New 2010). Knowledge of how diverse assemblages of beetles occupy multiple habitat strata could aid in informing the planning processes that lead to the conservation of these highly important yet declining environments.

Here, we address this question by sampling beetle adults across the main woodland strata in the New Forest, southern England, examining the compositional similarity between beetle species sampled within and between the strata. The New Forest is designated both a Site of Special Scientific Interest (SSSI) and a Special Area of Conservation (SAC), being of European importance (McLeod et al. 2005).

Both the ancient woodlands and woodland enclosures (oak plantations) of the New Forest are used in this investigation. The older enclosures were originally seeded hardwood plantations for the purpose of timber production, which when created were separated by stock fences (Tubbs 2001). The stock fencing has now mostly disappeared, merging the plantation enclosures into the ancient woodland areas; this now broadly forms a large, centralised, connected woodland. Due to the disappearance of the stock fencing, these sites are open to grazing by deer and commoners' livestock (Smith et al. 1992). These nine core woodland areas are very similar in floral composition, with the dominant tree species being beech (Fagus sylvatica) and oak (Quercus robur and $Q$. petraea). There is also an abundance of holly (Ilex aquifolium) in the understory of these core woodland sites (Peterken and Tubbs 1965).

Previous surveys observing vertical stratification of invertebrate assemblages have tended to use one single sampling method across a vertical transect, such as Malaise traps (MT), flight interception or light trapping. These trap types, however, depend on certain specific behaviours of the targeted invertebrates, for instance phototactic insects that move upwards towards light (Ozanne 2005). Sampling beetle assemblages as a whole using these methods across all strata is limited as many beetles are flightless and/or nocturnal, living on the ground and leaf litter. Attempting to avoid this sampling constraint (although, as we discuss later, sampling constraints are unavoidable) for this survey, we have used a mixed sampling protocol across vertical transects.

\section{Methods}

We sampled in nine core areas across four ancient woodlands and five woodland enclosures (oak plantations) in the New Forest National Park, southern England (See Supplemental data for Geolocation information). The sampling was undertaken within 1hectare plots in each. The sites that were chosen are evenly scattered within the forest, 
producing a good overall representation of the different woodland areas (see Carpenter et al. 2012 for sampling rationale and details of the plots).

Five sampling methods were chosen across the vertical transect: soil pits (SP), leaf litter samples by Winkler bag extraction (LL), pitfall traps (PF), Malaise traps (MT) and SLAM (Sea Land Air Malaise) traps (ST). These were all formed as part of the Natural History Museum's New Forest Quantitative Inventory (NFQI). The soil pits and leaf litter samples were taken in May 2010 and the pitfall trapping done in September 2011 (see Carpenter et al. 2012 for sampling design of ground and soil-level traps). Two MT were set up near the centre in each of the sampling plots to capture beetles flying around in the understory. Two SLAM traps were also used at each site to capture flying beetles in the lower canopy. These were suspended between $5 \mathrm{~m}$ and $7 \mathrm{~m}$ above the ground into the lower canopy. Traps of both types were left running for a week. The MT were used in June 2011, and the SLAM traps in June 2012. The data from all sampling methods were pooled within each plot for the purpose of multi-stratum comparison (i.e. there was only one set of species abundances for each method in each of the nine plots).

The extracted beetle specimens were identified to the named species level in the Soil Biodiversity Group laboratory. The species data for the soil pits, leaf litter and pitfall traps in our nine core plots were also used in Carpenter et al. (2012).

Compositional difference between and within samples were calculated using BrayCurtis dissimilarity (vegdist command, with method = 'bray'), and also species accumulation curves through rarefaction were both produced using the $\mathrm{R}$ vegan package (specaccum command, with method = 'rarefaction'; (Oksanen et al. 2011). The indicator species were calculated using the $\mathrm{R}$ indicspecies package (De Caceres and Legendre 2009). Species were classified into families/subfamilies and the distribution of species within subfamilies across sampling methods visualised in a correspondence analysis (CA) using CANOCO 5.0 (Ter Braak and Šmilauer 2012). The Staphylinidae, Chrysomelidae and Curculionidae were separated out into subfamily levels due to the various subfamilies having different behaviours.

\section{Results}

A total of 2412 individual beetles were sampled across the nine sample plots. These were identified and sorted to 157 species across 30 families, with 46 species which were significant indicators for within and between sampling methods (See Supplemental data for complete species list).

Between sampling methods, compositional similarity was low, averaging $6 \%$ and ranging from $<1 \%$ (between pitfall trap and slam traps) to $20 \%$ between Malaise and SLAM traps. The average within-method similarity was much greater at $39 \%$, ranging from $21 \%$ within the SLAM trap samples to $51 \%$ within pitfall trap samples (Table 1).

These results are borne out at the species level, where there were a number of indicator species both within and between sampling methods (Table 1), implying a stratification of those particular species to one or a few strata. This stratification can also be seen at the 'subfamily' level (Figure 1). In the CA ordination, axis 1 separates the Malaise and SLAM sampling from the other three sampling methods. This displays a distinct separation at a subfamily level between the understory and lower canopy from the ground-level sampling methods. 
Table 1. Indicator species results displaying significance within and between sampling methods from indicspecies analysis with compositional difference (\% similarity) from Bray-Curtis dissimilarity analysis. \% similarity $=(1-$ Bray-Curtis distance $) \times 100 . \%$ similarity of paired sites without indicator species: PF - MT: 2\%; PF - SP: 2\%; PF - ST: <1\%; SP - MT: 2\%; SP - ST: 5\%; SP - LL: 3\%; ST - LL: 5\%.

\begin{tabular}{|c|c|c|c|}
\hline $\begin{array}{l}\text { Sampling } \\
\text { method }\end{array}$ & $\begin{array}{c}\% \\
\text { similarity }\end{array}$ & $\begin{array}{c}\text { No. species } \\
\text { (IndVal, } P<0.05 \text { ) }\end{array}$ & Indicator species (family/subfamily) \\
\hline LL & $36 \%$ & 23 & $\begin{array}{l}\text { Notiophilus biguttatus (Carabidae), Megasternum concinnum } \\
\text { (Hydrophilidae), Acrotrichis intermedia agg (Ptiliidae), Geostiba } \\
\text { circellaris, Mocyta clientula, Mocyta fungi, Oxypoda annularis } \\
\text { (Aleocharinae), Habrocerus capillaricornis (Habrocerinae), Anthobium } \\
\text { unicolor (Omaliinae), Lathrobium brunnipes (Paederinae), Brachygluta } \\
\text { fossulata, Bryaxis puncticollis (Pselaphinae), Cephennium gallicum, } \\
\text { Neuraphes angulatus, Stenichnus collaris (Scydmaeninae), Philonthus } \\
\text { decorus (Staphylininae), Mycetoporus lepidus (Tachyporinae), } \\
\text { Cryptocephalus pusillus (Cryptocephalinae), Euophryum confine } \\
\text { (Cossoninae), Acalles ptinoides, Kykliocacalles roboris } \\
\text { (Cryptorhynchinae), Barypeithes araneiformis, Caenopsis waltoni } \\
\text { (Entiminae) }\end{array}$ \\
\hline MT & $44 \%$ & 8 & $\begin{array}{l}\text { Denticollis linearis (Elateridae), Malthodes minimus, Rhagonycha lignosa } \\
\text { (Cantharidae), Cartodere nodifer (Latridiidae), Anaspis maculata } \\
\text { (Scraptiidae), Rhagium bifasciatum (Cerambycidae), Aphthona } \\
\text { euphorbiae (Chrysomelidae) Phyllobius pyri (Entiminae) }\end{array}$ \\
\hline PF & $51 \%$ & 5 & $\begin{array}{c}\text { Carabus violaceus, Pterostichus madidus, Pterostichus nigrita (Carabidae), } \\
\text { Ocypus olens (Staphylinidae), Anoplotrupes stercorosus (Geotrupidae) }\end{array}$ \\
\hline SP & $41 \%$ & 1 & Nalassus laevioctostriatus (Tenebrionidae) \\
\hline ST & $21 \%$ & 1 & Trypodendron domesticum (Scolytinae) \\
\hline $\mathrm{LL}+\mathrm{MT}$ & $12 \%$ & 3 & $\begin{array}{l}\text { Agriotes pallidulus, Dalopius marginatus (Elateridae), Orchestes fagi } \\
\text { (Curculioninae) }\end{array}$ \\
\hline $\mathrm{LL}+\mathrm{PF}$ & $8 \%$ & 2 & Abax parallelepipedus, Nebria brevicollis (Carabidae) \\
\hline $\mathrm{MT}+\mathrm{ST}$ & $20 \%$ & 2 & Atheta vaga (Aleocharinae), Anaspis frontalis (Scraptiidae) \\
\hline $\begin{array}{l}\mathrm{LL}+\mathrm{MT}+ \\
\quad \mathrm{ST}\end{array}$ & $7 \%$ & 1 & Athous haemorrhoidalis (Elateridae) \\
\hline
\end{tabular}

Species accumulation curves show a wide range of species richnesses between the plots (Figure 2).

\section{Discussion}

Although these results are strongly suggestive of vertical stratification, they are likely to have some unavoidable sources of error. The main problem stems from biases associated with the sampling methods that rely on the different behavioural responses of each species. If the turnover gradient across the strata was continuous or if the targeted invertebrate group had homogeneous behaviour, it would be reasonable to use a single sampling method, although this is not the case within a highly varied stratified system. Studying this type of pattern is largely confounded by the different sampling methods which are constrained by the nature of the habitat (it is not possible to use MT to sample ground-dwelling beetles, or to use pitfall traps to study beetles which are mostly active in flight, and even if it were they would yield scanty data). One key sampling method which is missing from this analysis is flight interception traps (FITs) which along with Malaise trapping would give a greater overall representation of the understory invertebrate assemblage. Errors associated with sampling in different months and years may also lead to overestimates of dissimilarities between the strata. 


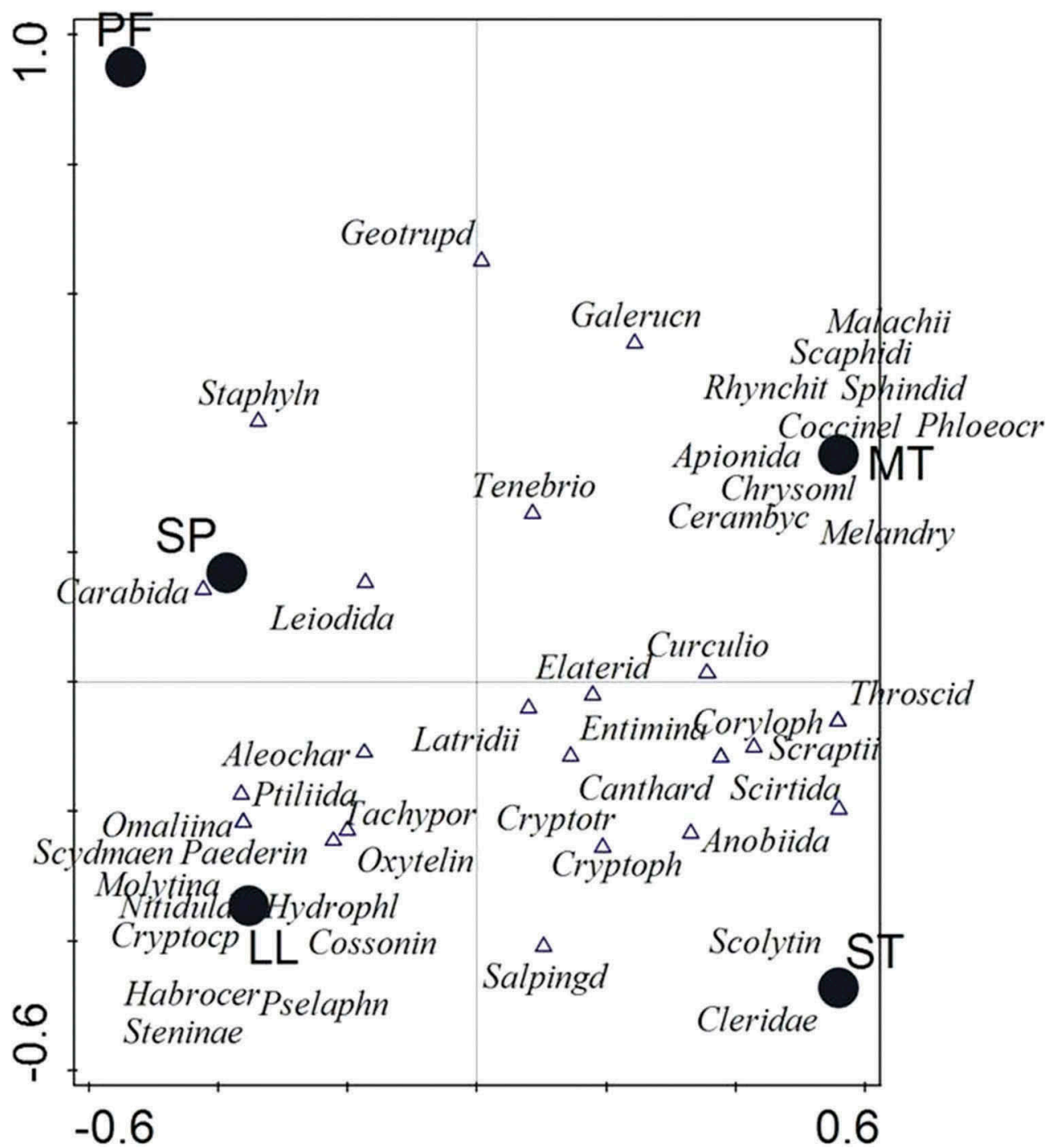

Figure 1. Correspondence analysis ordination of subfamily/family level showing separation between the sampling methods. Eigenvalue axis 1: 0.4953 , variation 45.14; axis 2: 0.2668 , variation 69.47 . Key to subfamily/family abbreviations - Carabida: Carabidae, Hydrophl: Hydrophilidae, Leiodida: Leiodidae, Omaliina: Omaliinae, Pselaphn: Pselaphinae, Phloeocr: Phloeocharinae, Tachypor: Tachyporinae, Habrocer: Habrocerinae, Aleochar: Aleocharinae, Oxytelin: Oxytelinae, Scaphidi: Scaphidiinae, Scydmaen: Scydmaeninae, Paederin: Paederinae, Staphyln: Staphylininae, Geotrupd: Geotrupidae, Scirtida: Scirtidae, Throscid: Throscidae, Elaterid: Elateridae, Canthard: Cantharidae, Ptiliida: Ptiliidae, Anobiida: Anobiinae, Malachii: Malachiidae, Sphindid: Sphindidae, Nitiduld: Nitidulidae, Cryptoph: Cryptophagidae, Coccinel: Coccinellidae, Coryloph: Corylophidae, Latridii: Latridiidae, Melandry: Melandryidae, Tenebrio: Tenebrionidae, Salpingd: Salpingidae, Scraptii: Scraptiidae, Cerambyc: Cerambycidae, Crytocp: Cryptocephalinae, Chrysoml: Chrysomelinae, Galerucn: Galerucinae, Rhynchit: Rhynchitidae, Apionida: Apionidae, Curculio: Curculioninae, Cossonin: Cossninae, Entimina: Entiminae, Molytina: Molytinae, Scolytin: Scolytinae. 


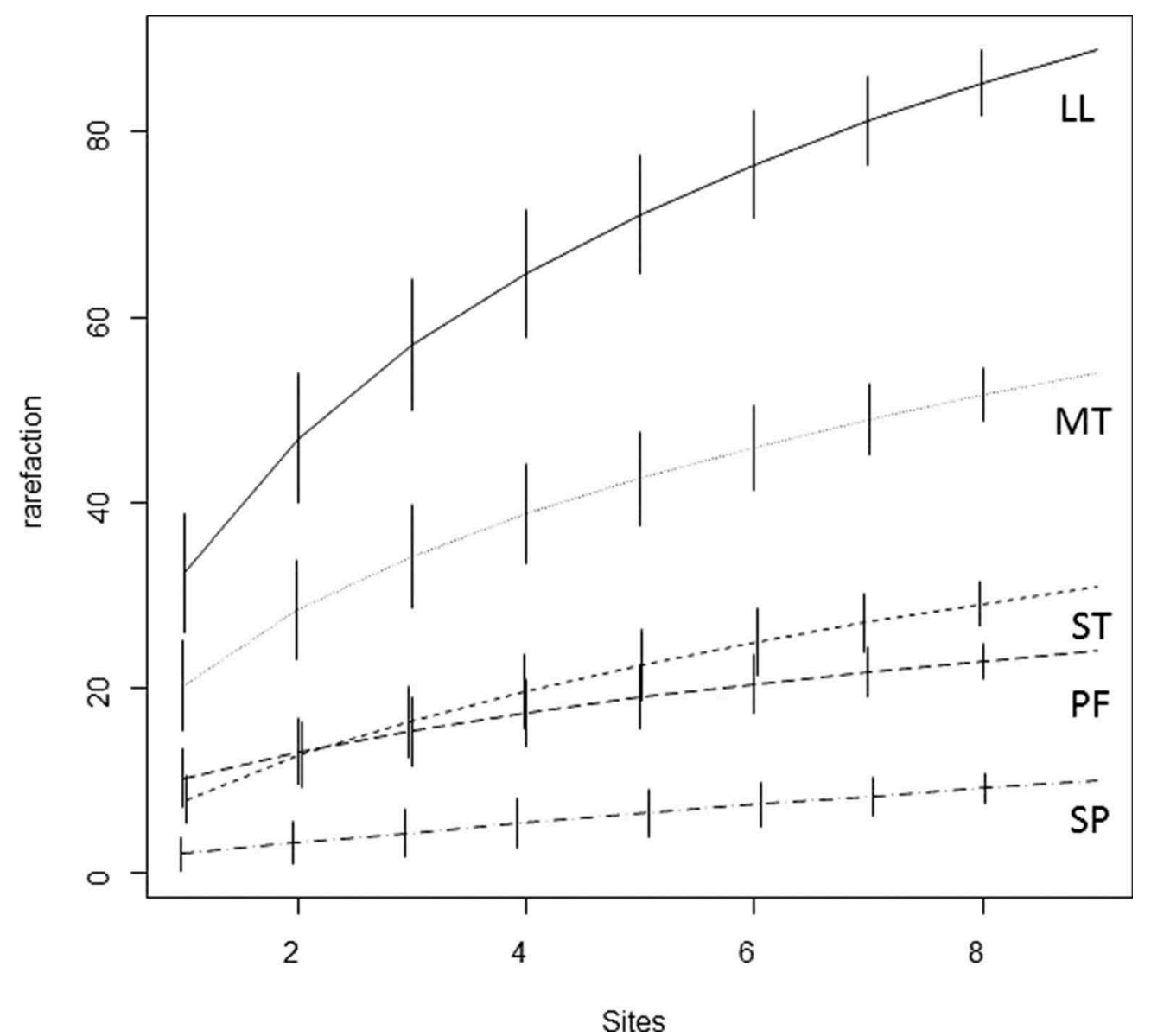

Figure 2. Species accumulation curves created by rarefaction for each sampling method. Vertical bars $=95 \%$ confidence limits around the species richness estimate.

Even with these limitations our results do point clearly towards large compositional differences between the vertical woodland strata. The leaf litter had by far the largest number of unique indicator species, amounting to over half of the total. The species accumulation curves in Figure 2 show the leaf litter also had by far the largest total number of species. Fourteen of them were Staphylinidae, particularly within the Scydmaeninae and Aleocharinae. Small litter-dwelling Staphylinidae generally feed on soil mesofauna (e.g. mites and collembola). Two species of Curculionidae, Acalles ptinoides and Kyklioacalles roboris, in the saproxylic subfamily Cryptorhynchinae were also significant indicators of the leaf litter. The species of this subfamily are generally woodfeeders subsisting predominantly on twigs, and are flightless thus having a low dispersal capability. Species with these low dispersal traits are known as relict species due to their inability to colonise isolated woodland patches (Buse 2012). The leaf litter plays a highly important role for beetles in the woodland ecosystem, acting as a food source while having a largely stable microclimate. Its complex three-dimensional structure also provides a diverse array of buffered microhabitats for the inhabiting invertebrates 
(Sayer 2005). The majority of arthropods in most forests are confined to inhabiting the low surface layers (Basset et al. 2003).

The pitfall sampling had very different indicator species within a different set of subfamilies (Table 1; Figure 1). These include larger Carabinae such as Carabus violaceus, and Staphylininae such as Ocypus olens. These species are generally large, long legged, active predators running freely at ground level. In contrast, soil pit sampling produced a very low diversity with one indicator species, Nalassus laevioctostriatus (Tenebrionidae), a soil cyanobacteria feeder (Carpenter et al. 2012).

Malaise trap samples had eight indicator species, the second highest number, as well as having the second highest rarefied species richness. Cantharidae, Cerambycidae and Scraptiidae make up the bulk of those indicator species (Table 1). Both cerambycids and scraptiids are saproxylic, a feeding group known to be more diverse and abundant in the understory than in the lower canopy (Bouget et al. 2011). Our results suggest that they are also uncommon at ground level. This result could be because of the extended larval development times in families such as the Cerambycidae, as they need large pieces of dead wood rather than the fine woody debris found on the forest floor (Wermelinger et al. 2007). The highest between-methods compositional similarity is between Malaise and SLAM trap samples (Figure 1). It is likely that many beetles fly regularly between the understory and lower canopy level. Atheta vaga (Staphylinidae: Aleocharinae), for example, is an indicator species for these two sampling methods combined, and is known to inhabit bird nests, feeding on fleas and mites (Krištofík et al. 2009). The SLAM traps sampled many of the same species as the Malaise traps, although with significantly fewer individuals. One probable reason for this is that the canopy generally has higher fluctuations in temperature and humidity and is more exposed to the wind. These factors may have a negative effect on the oviposition ability of saproxilic adults, driving them downwards towards the more environmentally stable understory (Vodka et al. 2009). The one indicator species from the SLAM trap method was Trypodendron domesticum (Curculionidae: Scolytinae). UK Scolytinae spend most of their lives burrowing in galleries inside woody branches (Cebeci and Ayberk 2010), particularly, in this species, within the lower canopy.

Elateridae have the largest number of shared species between the strata (Table 1), particularly between the Malaise and SLAM trap sampling. Athous haemorrhoidalis was the only indicator species found across three sampling methods (i.e. Winkler, Malaise and SLAM). The elaterids often live in the ground as larvae and emerge as adults and fly off into higher strata, sometimes swarming in large numbers (Crozier et al. 2003). This sequential occupation of three strata may well explain our results.

Our results suggest a strong stratification of adult beetles across the woodland environment, indicating its ecological complexity. This stratification is a result of the diverse array of microhabitats that beetles inhabit along the vertical gradient. This suggests that the whole woodland environment is vital for the maintenance of a high diversity of beetles and, in addition, that studies of single strata will not be at all characteristic of the habitat as a whole. This observation proves a strong argument for the lasting conservation and management of woodland strata continuity required by the highly diverse inhabiting beetle assemblage. 


\section{Acknowledgements}

We thank Dan Carpenter for helping to organise the fieldwork, and the volunteers of the Soil Biodiversity Group who helped with the fieldwork and the sorting of specimens back in the laboratory.

\section{Disclosure statement}

No potential conflict of interest was reported by the authors.

\section{Funding}

This project forms part of the ' New Forest Quantitative Inventory' funded by the Annual Fund, made possible by public donations to the Natural History Museum.

\section{References}

Baker PJ, Wilson JS. 2000. A quantitative technique for the identification of canopy stratification in tropical and temperate forests. For Ecol Manage. 127:77-86.

Barton PS, Manning AD, Gibb H, Lindenmayer DB, Cunningham SA. 2009. Conserving grounddwelling beetles in an endangered woodland community: multi-scale habitat effects on assemblage diversity. Biol Conserv. 142:1701-1709.

Basset Y, Hammond PM, Barrios H, Holloway JD, Miller SE. 2003. Vertical stratification of arthropod assemblages. In: Basset Y, Novoty V, Miller SE, Kitching RL, editors. Arthropods of tropical forests: spatio-temporal dynamics and resource use in the canopy. Cambridge: Cambridge University Press.

Bouget C, Brin A, Brustel H. 2011. Exploring the "last biotic frontier": are temperate forest canopies special for saproxylic beetles? For Ecol Manage. 261:211-220.

Buse J. 2012. "Ghosts of the past": flightless saproxylic weevils (Coleoptera: curculionidae) are relict species in ancient woodlands. J Insect Conserv. 16:93-102.

Carpenter D, Hammond PM, Sherlock E, Lidgett A, Leigh K, Eggleton P. 2012. Biodiversity of soil macrofauna in the New Forest: a benchmark study across a national park landscape. Biodivers Conserv. 21:3385-3410.

Cebeci HH, Ayberk H. 2010. Ambrosia beetles, hosts and distribution in Turkey with a study in the species of Istanbul province. Afr J Agric Res. 5:1055-1059.

Crozier S, Tanaka A, Vernon RS. 2003. Flight activity of Agriotes lineatus L. and A. obscurus L. (Coleoptera: elateridae) in the field. J Entomol Soc Brit Columbia. 100:91-92.

De Caceres M, Legendre P. 2009. Associations between species and groups of sites: indices and statistical inference. Ecology. 90:3566-3574.

Krištofík J, Mašán. P, Šustek Z, Karaska D. 2009. Arthropods in the nests of lesser spotted eagle (Aquila pomarina). Biologica. 64:974-980.

Lassua SA, Hochuli DF, Cassis G, Reid CAM. 2005. Effects of habitat complexity on forest beetle diversity: do functional groups respond consistently? Divers Popul. 11:73-82.

McLeod CR, Yeo M, Brown AE, Burn AJ, Hopkins JJ, Way SF, editors. 2005. The Habitats Directive: selection of Special Areas of Conservation in the UK. 2nd ed. Peterborough: Joint Nature Conservation Committee. Available from: www.jncc.gov.uk/SACselection

New TR. 2010. Beetles in Conservation. 1st ed. Chichester: Wiley-Blackwell Publishing.

Oksanen J, Guillaume BF, Kindt R, Legendre P, O'Hara RB, Simpson GL, Solymos P, Stevens MHH, Wagner H. 2011. Vegan: community ecology package version 1.17-12 [Internet]. [cited 2011 Jul] Available from: http://cran.r-project.org/web/packages/vegan/index.html

Ozanne CMP. 2005. Chapter 4 Sampling methods for forest understory vegetation. In: Leather SR, editor. Insect Sampling in Forest Ecosystems. Oxford: Blackwell Science Ltd. 
Peterken GF, Tubbs CR. 1965. Woodland Regeneration in the New Forest, Hampshire, Since 1650. J Appl Ecol. 2:159-170.

Sayer EJ. 2005. Using experimental manipulation to assess the roles of leaf litter in the functioning of forest ecosystems. Biol Rev. 80:1-31.

Shirt DB, editor. 1987. British Red Data Books 2. Insects. Peterborough: Nature Conservancy Council.

Smith KW, Burges DJ, Parks RA. 1992. Breeding bird communities of broadleaved plantation and ancient pasture woodlands of the New Forest. Bird Study. 39:132-141.

Ter Braak CJF, Šmilauer P. 2012. Canoco reference manual and user's guide: software for ordination (version 5.0). Ithaca (NY): Microcomputer Power.

Thomas PA, Packham JR. 2007. Ecology of woodlands and forests. New York: Cambridge University Press.

Tubbs CR. 2001. The new forest: history, ecology and conservation. 2nd ed. Lyndhurst (NJ): New Forest Ninth Centenary Trust.

Vodka S, Konvicka M, Cizek L. 2009. Habitat preferences of oak-feeding xylophagous beetles in a temperate woodland: implications for forest history and management. J Insect Conserv. 13:553562.

Wermelinger B, Flückiger PF, Obrist MK, Duelli P. 2007. Horizontal and vertical distribution of saproxylic beetles (Col., Buprestidae, Cerambycidae, Scolytinae) across sections of forest edges. J Appl Entomol. 131:104-114. 